\title{
Dynamic Rheological Behavior for Polymer Composites Filled with Particles
}

\author{
Du Miao, ZHENG Qiang, ${ }^{*}$ and YANG Hong Mei \\ Department of Polymer Science and Engineering, Zhejiang University, Hangzhou 310027, P. R. China \\ (Received : October 15, 2003)
}

\begin{abstract}
The dynamic rheological behavior of polymer composites filled with particles has been an interesting topic in polymer research fields because of the challenging physical problems and the increasing technological applications behind. In this paper, recent progress in studies on the characteristic dynamic rheological response for polymer composites was reviewed, mainly depending on the results by the authors, including HDPE filled with conductive particle, PS filled with Sn-Pb alloy, LDPE filled with MMT, PMVS filled with ultrafine silica and PP filled with ultrafine full-vulcanized powdered rubber. Based on the rheological measurements, some new fingerprints that responsed the evolution of morphology and strcutrure for these polymer composites were obtained. These new results provide guidelines for fabricating new composite materials.
\end{abstract}

Key Words: Dynamic rheological behavior / Polymer composite / Particle

\section{INTRODUCTION}

Fillers are used extensively to improve the mechanical properties of polymer matrix resins such as stiffness, strength, hardness. These properties usually increased with increasing amounts of fillers added. The incorporation of fillers into polymers also alters their flow behavior and thus processability. Studies on rheological properties of particlefilled polymers in the molten state have been attracted researcher's attentions. ${ }^{1-4)}$

Dynamic rheology testing is believed to be a preferential method for dealing with the structure/morphology of materials because the structure of materials exposed to the testing processes is not destroyed under small-strain amplitude. ${ }^{5)}$ The so-called second plateau, a phenomenon in dynamic viscoelastic functions, for example, the storage modulus $G^{\prime}$ and loss modulus $G^{\prime \prime}$, which exhibit a special response corresponding to linear viscoelasticity, is thought to give important information concerning the viscoelastic behavior of multicomponent/multiphase polymer systems at very low frequencies (terminal region). ${ }^{6}$ Moreover, the appearance of a second plateau in the terminal region is considered to be induced by the formation of a higher order structure of particles, for example, an agglomerated structure, skeleton, or network structure. ${ }^{7)}$

* To whom correspondence should be addressed:

Tel: +86-571-87952522, Fax: +86-571-87952522, E-mail: zhengqiang@zju.edu.cn
Compared with the rheological behavior of the pure polymer matrix, polymer composites generally exhibit pronounced elastic properties and long relaxation times. ${ }^{8-10)}$ The rheological behavior of a filled polymer composite is governed first by the properties of both the polymer matrix and incorporated fillers and is then influenced by the volume fraction and agglomerations of the filler particles and the interfacial adhesion between the filler and matrix. ${ }^{11-13)}$ On the other hand, dynamic rheological measurement is an effective method to characterize the morphological and structure of the multicomponent and/or multiphase polymer composites. ${ }^{14-16)}$ The rheological property changes of a polymer matrix induced by filler incorporation are thought to be caused by two factors. One is the mechanical coupling between filler and polymer matrix, ${ }^{12,13)}$ the other one is the interface morphological structure depending on the interfacial adhesion or adsorption between the phases. Besides the previously mentioned causes, the matter state (solid or liquid) of fillers also has a significant influence on the rheological behavior of composite. Up to date, little attention was paid to these aspects.

Recent years, we highlight the current research on the dynamic rheological behavior of polymer composites mixtures containing either traditional fillers or nanoscope fillers, such as HDPE filled with conductive particle, PS filled with $\mathrm{Sn}-\mathrm{Pb}$ alloy, LDPE/MMT nanocomposites, PMVS filled with ultrafine silica and PP filled with ultra-fine full-vulcanized powdered rubber. All the works summarized in this paper were 
carried out in Zheng's rheology group in Department of Polymer Science and Engineering, Zhejiang University, China.

\section{POLYMER FILLED WITH TRADITIONAL PARTICLES}

First, we systematically probed the effects of the heat treatment on the dynamic viscoelastic properties of carbon black (CB)-filled high-density polyethylene(HDPE) in the molten state. ${ }^{17)}$ When the temperature was above $180^{\circ} \mathrm{C}$ in an air atmosphere, the storage modulus $G^{\prime}$, loss modulus $G^{\prime \prime}$, and loss tangent $\delta$ showed particular characteristics. In the lowfrequency $(\omega)$ region, the modulus increased with increase of the testing time while the $\tan \delta$ obviously decreased as shown
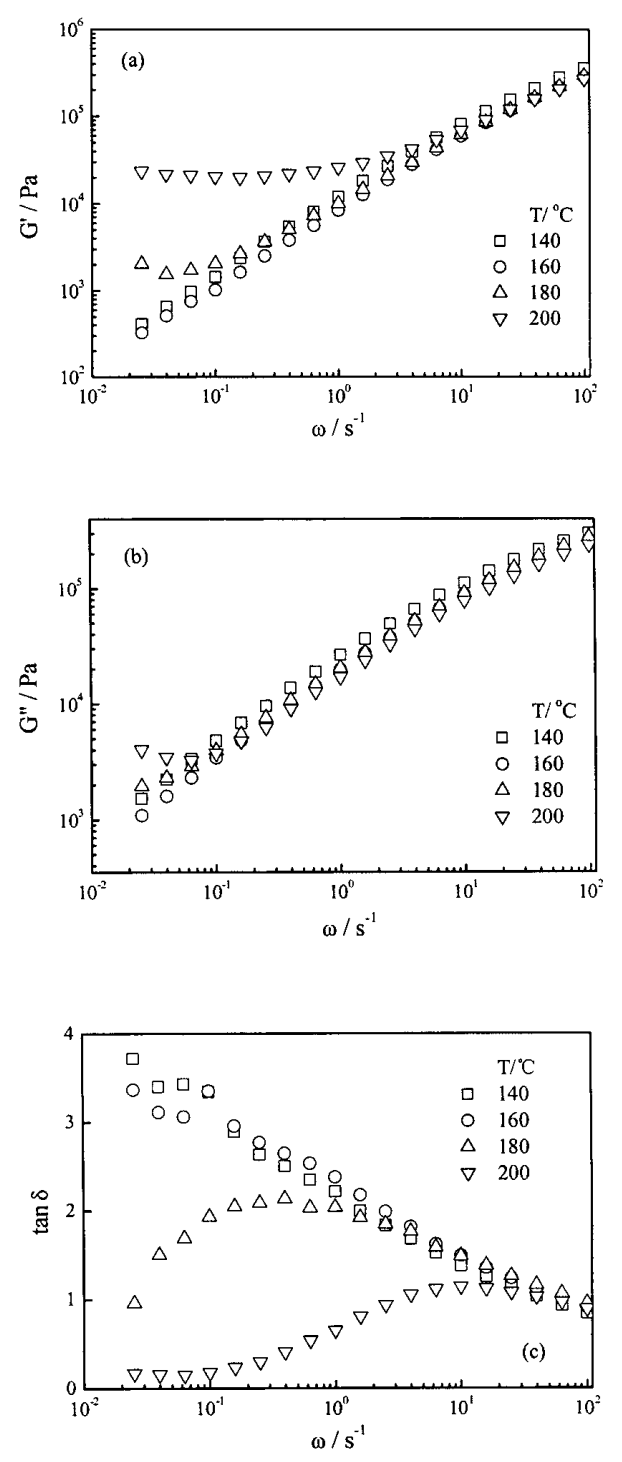

Fig.1 Frequency dependence of dynamic viscoelasticalfunctions for $\mathrm{CB} /$ $\operatorname{HDPE}(14 / 100)$ held at a $140,160,180$, and $200^{\circ} \mathrm{C}$ atmosphere for 70 min: (a) $G^{\prime}$; (b) $G^{\prime \prime}$; (c) $\tan \delta$. in Figs. 1 and 2. Also, the higher the temperature, the more notable was the change. We can detect these changes from the deviation of $G^{\prime}\left(G^{\prime \prime}\right)$ against $\omega$ plots from the linearity and the appearance of a characteristic plateau phenomenon. The width and height of the modulus plateau increased with increase of the temperature. When temperature was below $180^{\circ} \mathrm{C}$, the testing time and the temperature had no effect on the viscoelastic parameters of HDPE. However, if we used 99\% nitrogen gas as the atmosphere, substituting for air, the viscoelastic parameters revealed an undiscernable change, different from that in an air atmosphere (Fig.3). No changes were found under the protection of the antioxidant B215. These phenomena indicated that HDPE could be oxidized at a temperature higher than $180^{\circ} \mathrm{C}$ and $\mathrm{N}_{2}$ gas and an antioxidant
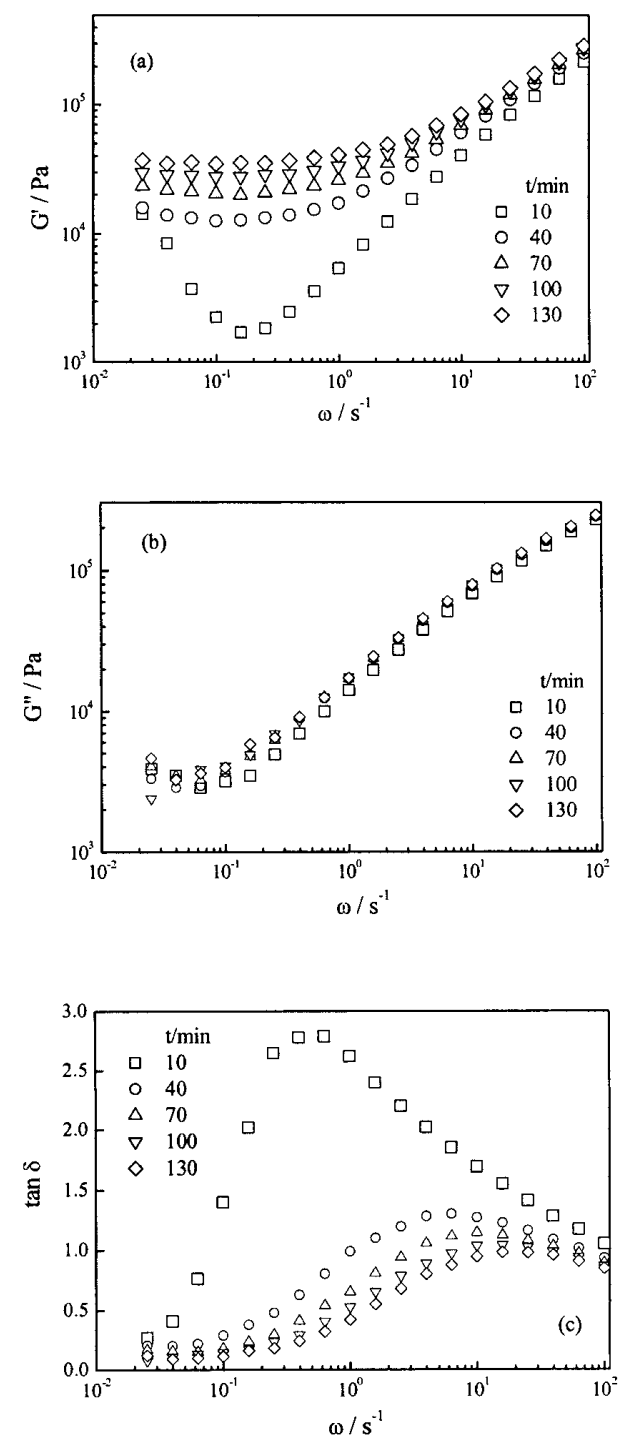

Fig.2 Frequency dependence of dynamic viscoelastical functions for $\mathrm{CB} / \mathrm{HDPE}(14 / 100)$ held at a $200^{\circ} \mathrm{C}$ atmospherefor $10,40,70,100$, and $130 \mathrm{~min}$, respectively: (a) $G^{\prime}$; (b) $G^{\prime \prime}$; (c) $\tan \delta$. 
agent could prevent HDPE from crosslinking. It is believed that the plots of $\tan \delta$ against $\omega$ can more sensitively reflect the irreversible change of HDPE as compared with the plots of modulus against $\omega$.

It is well-known that for the conductive particle-filled polymer composites the negative temperature coefficient effect following the positive temperature coefficient (PTC) transition is harmful to the application of such composites. To overcome the disadvantage a novel electrical composite was developed, in which PTC transition is achieved by the addition of a low-melting-point $\left(T_{m}\right)$ alloy filler. ${ }^{18)}$ Furthermore, a new composite possessing double PTC transition was also developed according to the same principle. ${ }^{19)}$ In previous research ${ }^{20-23)}$, rigid particles, such as mineral fillers, and deformable droplets, such as rubber fillers, softeners, and lubricants, have been two main kinds of fillers. Rigid particles are the reinforcements of composites, but deformable droplets usually act as a polymer processing promoters. In processing temperatures of the previous systems, however, no changes in the matter state occurred. The performance of these composites can be controlled by the change of the matter state during the melting of fillers. The rheological behavior of both polymer matrix and fillers are believed to play an important role in the ultimate morphology and properties of the composites. The
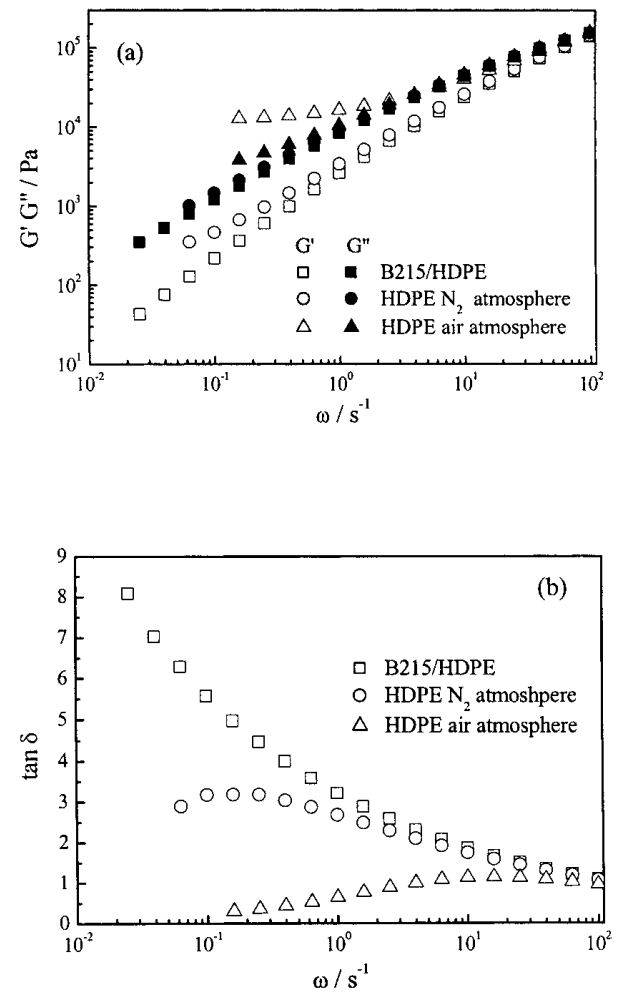

Fig.3 Frequency dependence of dynamic viscoelastical functions for HDPE held at $200^{\circ} \mathrm{C}$ for $40 \mathrm{~min}$. dynamic rheological behavior of polystyrene filled with low$T_{m} \mathrm{Sn}-\mathrm{Pb}$ was investigated at temperatures below and above the $T_{m}$ of the alloy, $183^{\circ} \mathrm{C} .^{24)}$ In the whole temperature range of interest, there existed a secondary plateau in the plots of the dynamic storage modulus versus $\omega$ at low- $\omega$ s, and the influences of alloy content and temperature on the plateau were related to the matter state (liquid or solid) of the alloy. We believe that the secondary plateau observed below the $T_{m}$ was due to the network-type structure formed by the agglomeration of solid filler particles, whereas the plateau above the $T_{m}$ was due to the deformability and relaxation of the liquid alloy droplets. The difference in dynamic viscoelastic behavior of the composites below and above the $T_{m}$ was verified by the Cole-Cole diagrams (Figs.4 and 5). It is believed that the alloy fillers retarded the relaxation processes for polystyrene (PS) melts when the temperature was lower than the $T_{m}$. However,
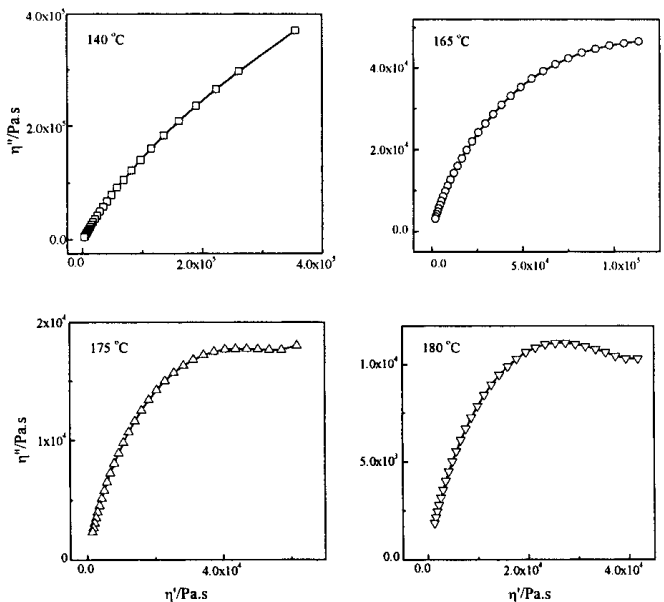

Fig.4 Cole-Cole diagrams of PS filled with 25 vol \% $\%$-Pb alloy at various temperatures before the alloy melted.
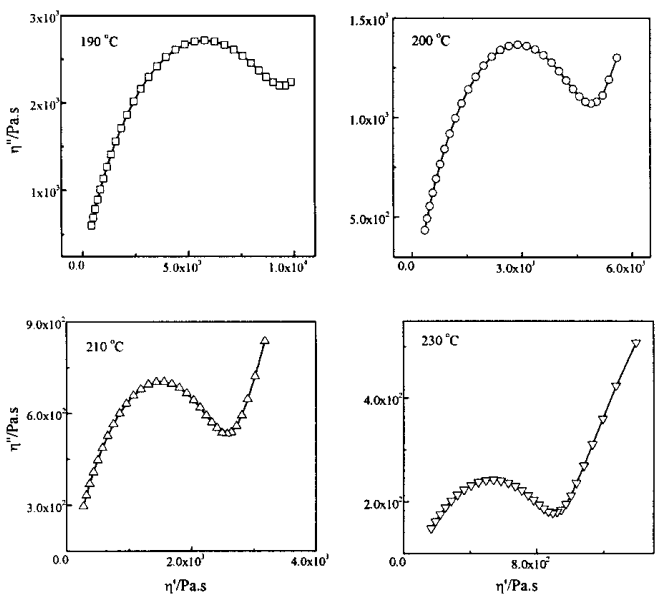

Fig.5 Cole-Cole diagrams for PS filled with 25 vol \% Sn-Pb alloy at temperature above the alloy $T_{m}$ 
there existed two separated relaxation processes when the temperature was higher than the $T_{m}$, that is, the high- $\omega$ relaxation of the phases and low- $\omega$ relaxation of the droplets.

On the other hand, the effect of filler surface treatment on the dynamic rheological behaviors of polystyrene filled with $\mathrm{Sn}-\mathrm{Pb}$ alloy particles was also tested below and above the $T_{m}{ }^{25)}$ The mechanical relaxation relevant to the $T_{m}$ of the alloy in the composite was diminished by the filler surface pretreatment. In the whole temperature range of interest, there existed a secondary plateau of the storage modulus at low- $\omega$ s. The effect of alloy particle surface treatment on the plateau was related to the matter state change (from solid to liquid) of the alloy. Above the $T_{m}$, the surface treatment of the alloy affected the secondary plateau, but below the $T_{m}$, it did not.

\section{POLYMER FILLED WITH NANOSCOPE PARTICLES}

Due to possessing special structure/morphology, polymer filled with nanoscope particles, i.e. nanocomposites, exhibit some particular characteristics as compared with the pristine polymers ${ }^{26-28)}$. The physical, thermal and mechanical properties of the composites have been enhanced with very low inorganic content. Many results have shown that the dynamic rheological properties of nanocomposites were different from the conventional particle-filled polymer composites.

Many researchers applied themselves to their study on rheology of polymers based montmorillonite intercalated or exfoliated nanocomposites. Much interest has focused on linear viscoelastic properties for the montmorillonite nanocomposites melts with matrix polymers such as poly $(\varepsilon-$ caprolacton) ${ }^{29)}$, nylon $6^{29,30)}$, polystyrene ${ }^{31)}$, polystyrenepolyisoprene ${ }^{32)}$, and polypropylene. ${ }^{33-34)}$ All studies showed rather unique results compared with traditional particle-filled polymers. It can be found that the systems exhibited a trend of pseudo solid-like at lower- $\omega$ s even the montmorillonite loading as low as 2 3 wt. \%, suggesting that network structure of the filler was formed during preparing such nanocomposites at relatively low filler content, typically about $3 \mathrm{wt} . \%$ or lower. But application of a large amplitude oscillatory stress for relatively long time will lead to a dynamic modulus drop and a pseudo solid-like behavior weakened.

It is well accepted that low density PE (LDPE) is a nonpolar polymer and can not intercalate into MMT layers easily because of the poor compatibility between them. In this case even though under the strong stress given by twin screw, the polymer intercalation is not so efficient. Incorporation of ethylene vinyl acetate copolymer (EVA), a polar polymer, into these system will act as a compatibilizer and will improve the interaction between polymer and modifiers. As a result, the polymers intercalate into MMT layers more easily. We used an advanced rheometric expansion system (ARES) to probe the rheological behavior of MMT/LDPE nanocomposite melts in order to understand the dynamic viscoelastic response of the nanocomposite. ${ }^{35)}$ The results revealed that the dynamic viscoelastic properties of the composites strongly depended on intercalation of polymer, and exhibited dramatic change with altering intercalation conditions (Fig.6). Only when modified montmorillonite content was about $3 \mathrm{wt} \%$, the composite showed a trend of pseudo-solidlike at lower $\omega$ s.

While, the layers would be aligned under large amplitude
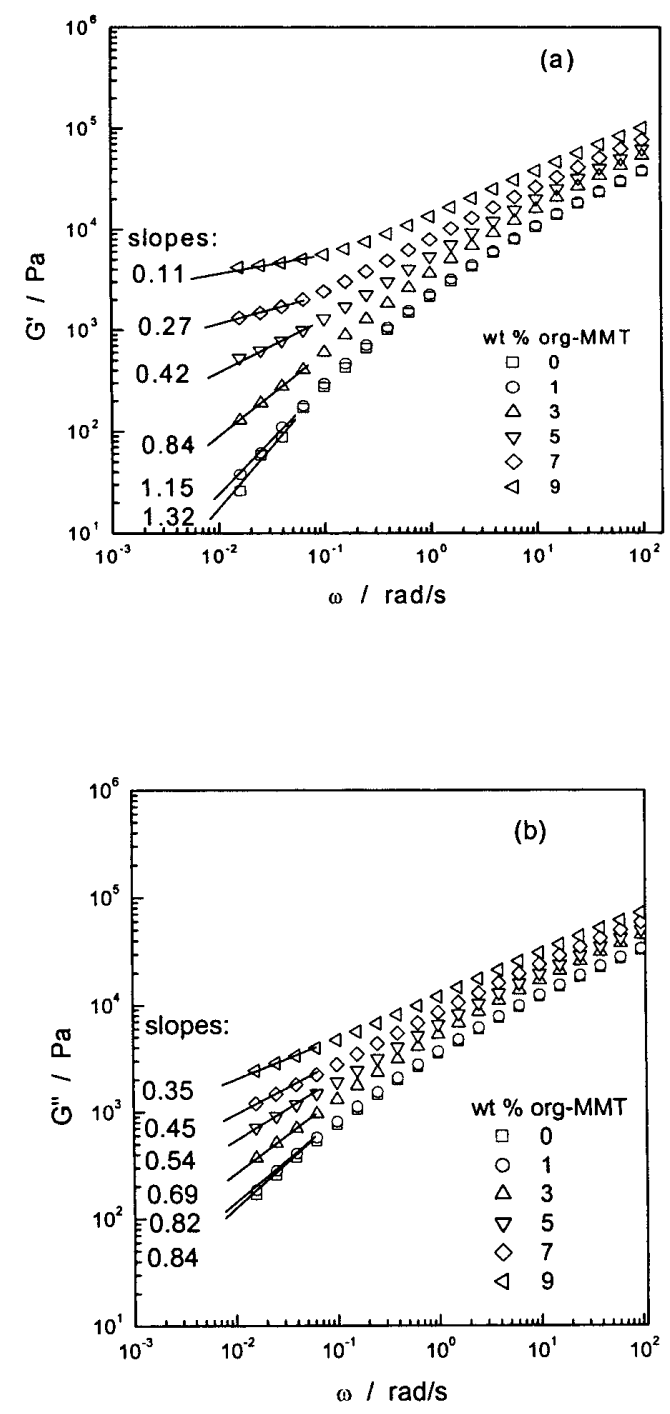

Fig.6 Dependence of (a) storage module $G^{\prime}$ and (b) loss module $G^{\prime \prime}$ on frequency $\omega$ for the composites with different content of org$\mathrm{MMT}$ at $150^{\circ} \mathrm{C}$ before large amplitude oscillatory shear. 
oscillatory shear for long time. ${ }^{36)}$ As a result (Fig.7), the dependence of dynamic modulus on low- $\omega$ s would remarkably changed from solid-like to more liquid-like. Exfoliation of silicate layers and the more loadings of montmorillonite exfoliated into the composites would be two main reasons which caused composites melts exhibiting abnormal linear viscoelastic behavior. The montmorillonite layers would be aligned along the stress direction and as a result, the dependence of dynamic modulus on the $\omega$ would be quite different before and after suffering from large amplitude oscillatory shear.

The special toughening effect on polypropylene (PP) using ultra-fine powdered rubber (UFPR) has attracted attention recently ${ }^{37)}$ because the toughness, stiffness and heat resistance of PP can be improved simultaneously through incorporation
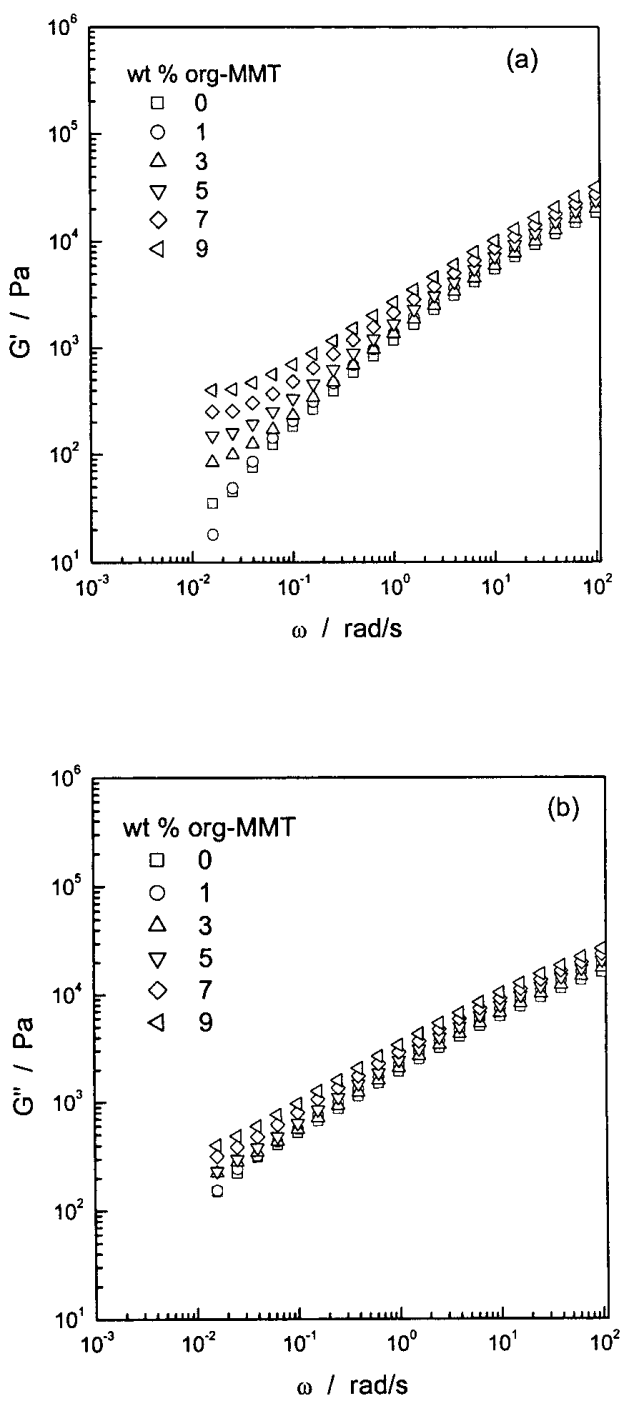

Fig.7 Dependence of (a) storage module $G^{\prime}$ and (b) loss module $G^{\prime \prime}$ on frequency $\omega$ for the composites with different loading of org-MMT at $150^{\circ} \mathrm{C}$ after large amplitude oscillatory shear. of a small amount of UFPR. Few results concerning the rheological behavior of UFPR / polymer systems have been reported until now. The dynamic rheological characteristics of PP filled with UFPR, which have a diameter of roughly $100 \mathrm{~nm}$, were also studied through dynamic rheological measurements using ARES in our group. Different from LDPE/MMT, only when UFPR content was higher than 10 $\mathrm{wt} \%$, the composite showed a trend of pseudo-solidlike at low$\omega \mathrm{s}^{38-40)}$ (Fig.8), which is partly because the UFPR did not disperse in nanoscope in the composites. The effect of temperature on the Cole-Cole diagrams of UFPR/PP composites, as shown in Fig.9, revealed a tail develops on the right-hand side of the arc for PP containing $20 \mathrm{wt} \%$ particles when the temperature is beyond $190^{\circ} \mathrm{C}$. This phenomenon declared that the higher the temperature, the more easily move the filer particles. In other words, the increase of temperature resulted in the aggregation of UFPR particles according to previous reports by author that the appearance of the tail was

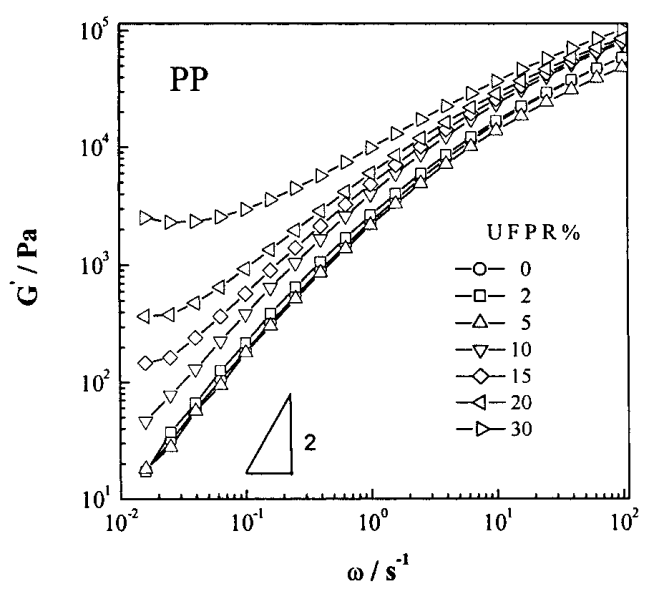

Fig.8 Frequency dependence of dynamic storage modulus $\mathrm{G}^{\prime}$ for PP samples with various UFPR contents measured at $200^{\circ} \mathrm{C}$.

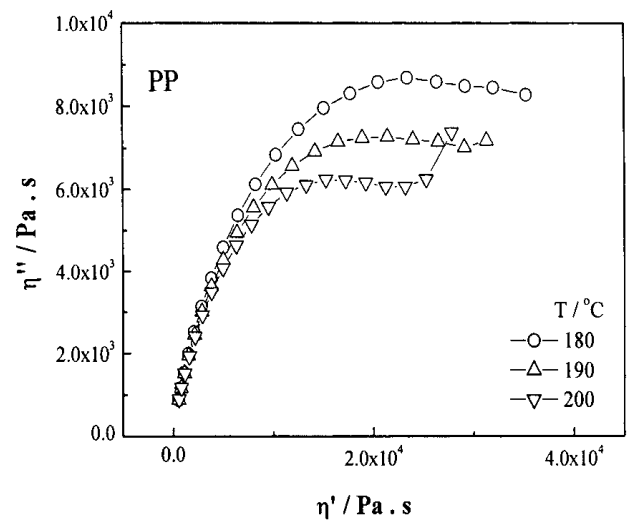

Fig.9 Cole-Cole diagrams of PP filled with $20 \mathrm{wt} \%$ UFPR at different temperatures. 
related with the formation of heterogeneous structure / morphology. ${ }^{24)}$ Hence, it is suggested that the structure of the PP containing $20 \mathrm{wt} \%$ UFPR is homogeneous when temperature is below $190^{\circ} \mathrm{C}$.

For polymethylvinylsiloxane (PMVS) filled with ultra-fine silica $\left(\mathrm{SiO}_{2}\right)$ which have a diameter of roughly $20 \mathrm{~nm}^{41)}$, only an incorporation of $5 \% \mathrm{SiO}_{2}$ into $\mathrm{PMVS}$ at $25^{\circ} \mathrm{C}$ could be enough to impact a significant increase on the storage modulus $\left(G^{\prime}\right)$ of the uncured system (Fig.10), which is believed to be caused by the strong interactions among silica filler. But no distinct "second plateau" was observed even the content of $\mathrm{SiO}_{2}$ approached $20 \%$ in this system. We owe partly due to the surface esterification of silanols and partly by the unvulcanized PMVS. Meanwhile, strain-dependence of $G^{\prime}$ related to Payne effect was observed upon increasing strain amplitude (Fig.11).

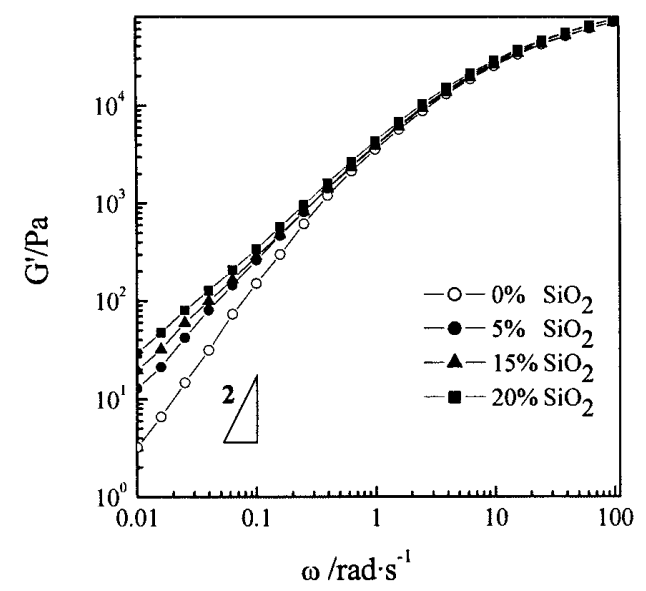

Fig.10 Plot of dynamic storage modulus $\left(G^{\prime}\right)$ versus frequency $(\omega)$ at $25^{\circ} \mathrm{C}$ for PMVS filled with ultrafine $\mathrm{SiO}_{2}$.

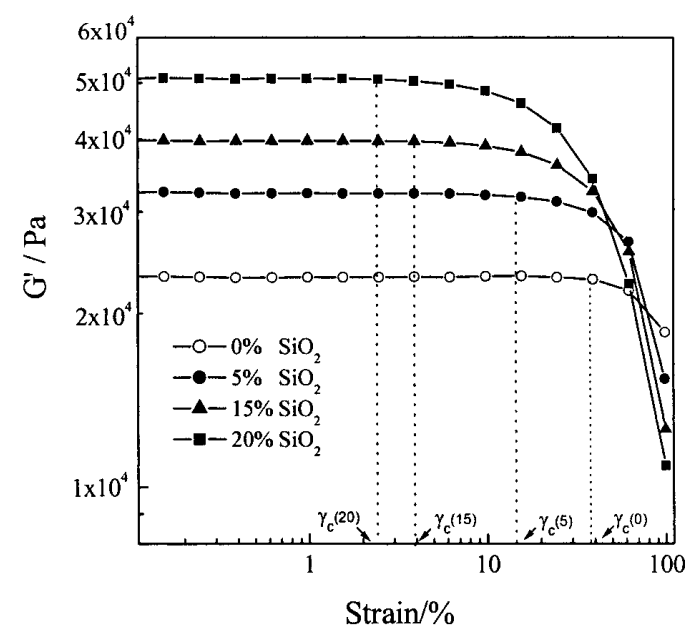

Fig.11 Plot of dynamic storage modulus $\left(G^{\prime}\right)$ versus strain $(\gamma)$ at $25^{\circ} \mathrm{C}, 10$ $\mathrm{Hz}$ for PMVS filled with ultrafine $\mathrm{SiO}_{2}$.

\section{CONCLUSIONS}

The above studies reveal that the dynamic rheological response can be used to characterize the morphology/or structure of polymer composites filled with either traditional particles or nanoscope particles. It is pointed out that each of these five composites have themselves characterized rheological response for morphology evolution. The relationship between dynamic rheological behavior and morphology described here just the examples of the distinctive response that occur in polymer composites filled with traditional or nanoscope particles. Additional studies are needed to probe the nature of dynamic rheological behavior to describe quantitatively the relationship between dynamic rheological response and morphology evolution.

\section{Acknowledgement}

This work was supported by the National Natural Science Funds for Distinguished Young Scholars (grant 50125312), Key Program of National Science Foundation of China (grant 50133020) and Special Funds for Major State Basic Research Projects (Grant No. G1999064800).

\section{REFERENCES}

1) Aoki Y, Macromolecules, 20, 2208 (1987).

2) Li L, Masuda T, Polym Eng Sci, 30, 841 (1990).

3) Bousmina M, Muller R, J Rheol, 37, 663 (1993).

4) Memon N A, Muller R, J Polym Sci, Part B: Polym Phys, 36, 2623 (1998).

5) Utracki L A, Polymer Alloys and Blends, Carl Hanser: New York, pp 131-174 (1989).

6) Takahashi M, Li, L, Masuda T, J Rheol, 33, 709 (1989).

7) Onogi S, Matsumoto T, Polym Eng Rev, 1, 45 (1981).

8) Graebling D, Muller R, Colloids Surf, 55, 89 (1991).

9) Graebling D, Benkira A, Gallot Y, Muller R, 30, 301 (1994).

10) Graebling D, Muller R, Palierne J F, Macromolecules, 26, 320 (1993).

11) Chazeau L, Paillet M, Cavaille J Y, J Polym Sci Phys, 37, 2151 (1999).

12) Liang J Z, Li R K Y, Tjong S C, Polym Int, 48, 1068 (1999).

13) Alberola N D, Fernagut F, Mele P, J Appl Polym Sci, 63, 1029 (1997).

14) Zheng Q, Du M, Yang B B, Wu G, Polymer, 42, 5743 (2001).

15) Peng M, Zheng Q, Chin J Polym Sci, 18, 565 (2000).

16) Han C D, J Appl Polym Sci, 32, 3809 (1986).

17) Wu G, Song Y H, Zheng Q, Du M, Zhang P J, J Appl Polym Sci, 88, 2160 (2003). 
18) Li R K Y, Liang J Z, Tjong S C, J Mater Process, 79, 89 (1998).

19) Lipatov Y S, Adv Polym Sci, 22, 1 (1977).

20) McCabe C C, Mueller N, Trans Soc Rheol, 5, 329 (1961).

21) White J L, Crowder J W, J Appl Polym Sci, 18, 1013 (1974).

22) Maiti S N, Mahapatro P K, Polym Compos, 9, 291 (1988).

23) Taylor G I, Proc R Soc London Ser A, 146, 501 (1934).

24) Zheng Q, Zhang X W, Pan Y, Yi X S, J Appl Polym Sci, 86, 3166 (2002).

25) Zhang XW, Pan Y, Zheng, Q, Yi X S, J Appl Polym Sci, 86, 3173 (2002).

26) Cho J W, Paul, D R, Polymer, 42, 1083 (2001).

27) Kawasumi M, Hasegawa N, Kato M, Usuki A, Okada A, Macromolecules, 30, 6333 (1997).

28) Zanetti M, Camino G, Thomann R, Mulhaupt R, Polymer, 42, 4501 (2001).

29) Krishnamoorti R, Giannelis E P, Macromolecules, 30, 4097 (1997).
30) Fornes T D, Yooh P J, Keskkula H, Paul D R, Polymer, 42, 9929 (2001).

31) Hoffmann B, Dietrich C, Friedrich R, Mulhaupt R, Macromolecule Rapid Communication, 21, 57 (2000).

32) Ren J, Silva A S, Krishnamoorti R, Macromolecules, 33, 3739 (2000).

33) Solomon M J, Almusallam A S, Seefeldt K F, Macromolecules, 34, 1864 (2001).

34) Galgali G, Ramesh C, Lele A, Macromolecules, 34, 852 (2001).

35) Yang H M, Zheng Q, Chin Chem L, 2003 (In press).

36) Yang H M, Zheng W, Du M, Xu B, 2003 (Submitted to).

37) Liu $Y$ Q, Zhang X H, Wei G S, Gao J M, Huang F, Zhang M L, Guo M F, Qiao J L, Chin. J Polym Sci, 20(2), 93 (2002).

38) Cao Y X, Du M, Zheng Q, Chin Chem L, 2003 (In press).

39) Zheng Q, Cao Y X, Du M, J Mat Sci Lett, 2003 (In press).

40) Zheng Q, Cao Y X, Du M, Chin J Polym Sci, 2003 (In press).

41) Hu H G, Zheng Q, Tao X L, Chem J Chin Univ, 2003 (In press). 